\title{
RESPONSE FROM THE EDITOR TO TOWARD OPEN DATA POLICIES IN PHONETICS: WHAT WE CAN GAIN AND HOW WE CAN AVOID PITFALLS
}

\author{
BARBOSA, Plínio A. ${ }^{1}$ \\ ${ }^{1}$ University of Campinas
}

It is a great pleasure to welcome this letter by eleven prominent researchers of the field of phonetics who open a very important discussion that touches a crucial aspect of open science: open data. The main point presented by this letter is that "journals publishing original research articles about phonetics decide that archiving of primary data is now a prerequisite for submissions" by understanding that availability of data is a point related to "the same activity that results in the publication of research papers".

This journal subscribes entirely with the authors' appeal to the scientific community, which is a first step to stimulate journals' editors and publishers to reconsider or review current practices. This is especially important when research is partially or fully financed by public money, but not only because of that. Science is characterized by reproducibility and to a work to be reproducible primary data must be available, that is, data should be open, freely accessible.

In a continuing preoccupation with this issue, our university determined, with the exceptions mentioned in the letter, that all projects proposed by any researcher must be accompanied by a plan of archiving in the university repository here: $<$ http://repositorio.unicamp.br/>.

As one of JoSS' editor I am very happy to publish this letter, which reflects our thinking for open science in all aspects related to this very word "open". 